\title{
Mutation-Specific Survival of Inherited Breast Cancer
}

P. Møller ${ }^{1}, \AA$ A. Borg ${ }^{2}$, G. Evans ${ }^{3}$, N. Haites ${ }^{4}$, C.M. Steel ${ }^{5}$, H. Vasen ${ }^{6}$, H. Gregory ${ }^{4}$, S. Hodgson ${ }^{7}$, J. Apold ${ }^{7}$, F. Lalloo ${ }^{3}$, L. Mæhle ${ }^{1}$, E. Anderson ${ }^{5}$, K. Heimdal ${ }^{1}$ and the Biomed 2 Demonstration Programme on Inherited Breast Cancer

${ }^{1}$ Unit of Medical Genetics, The Norwegian Radium Hospital, N-0310 Oslo, Norway

${ }^{2}$ University of Lund, Sweden

${ }^{3}$ St. Mary's Hospital, Manchester, UK ${ }^{4}$ Aberdeen University Medical School, Aberdeen, UK

${ }^{5}$ Edinburgh Breast Unit \& University of St. Andrews, UK

${ }^{6}$ Foundation for Detection of Hereditary Tumors, Leiden, the Netherlands

${ }^{7}$ Guy's Hospital, London, UK

As described in the accompanying abstract "Effectiveness of early diagnosis of inherited breast cancer", 5-year event-free survival of prospectively detected inherited breast cancer is
$>80 \%$. This is substantially better than retrospective reports on BRCA1 mutation carriers.

The diagnosed cancers were in young women. In both the Norwegian and Manchester series, time in preclinical detectable stage for inherited cancers is comparable with that for sporadic cancers. That is, time-length bias may be limited to about one year. If so, the observed event-free survival is better than historical data.

Breast cancer in BRCA1 mutation carriers is reported to have an unfavorable prognosis. If this is so, it implies that the other inherited breast cancers may have a better prognosis than the overall estimate obtained.

Preliminary results of mutation testing of the prospective cancers and comparisons of stage at diagnosis and event-free survival between BRCA1 mutation carriers and non-carriers will be presented.

We concluded that an international multicenter study is needed to consider the possibility that BRCAl mutation carriers should be offered different management than non-carriers. 


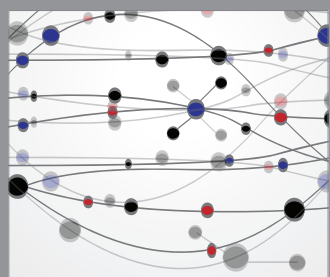

The Scientific World Journal
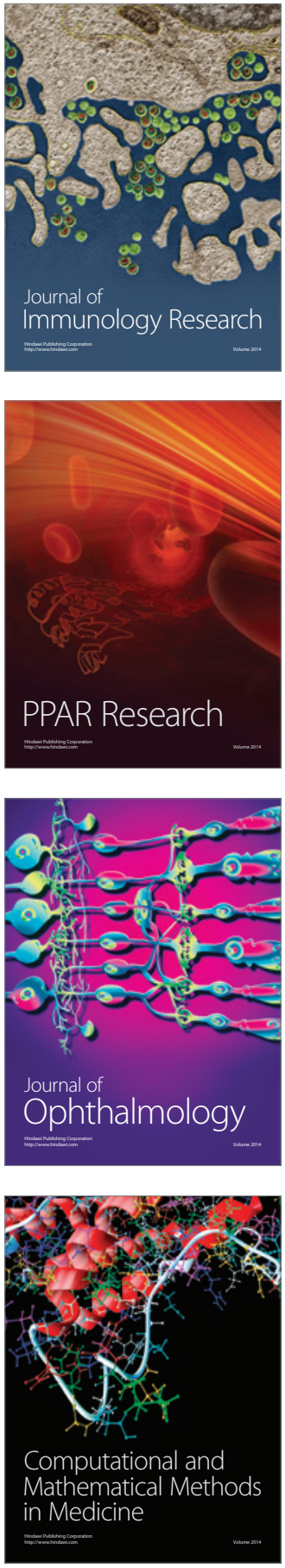

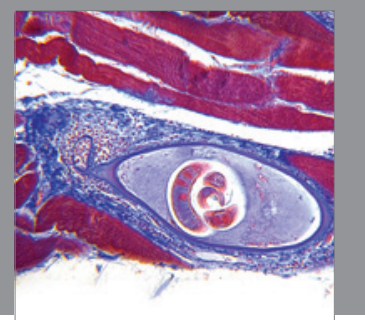

Gastroenterology

Research and Practice
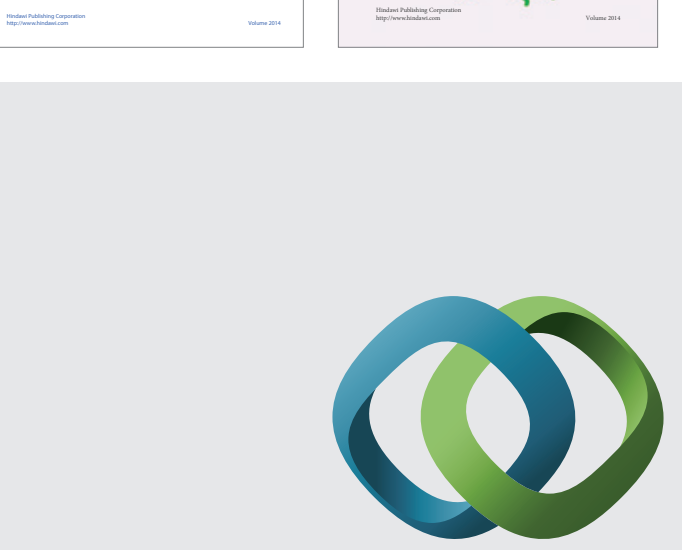

\section{Hindawi}

Submit your manuscripts at

http://www.hindawi.com
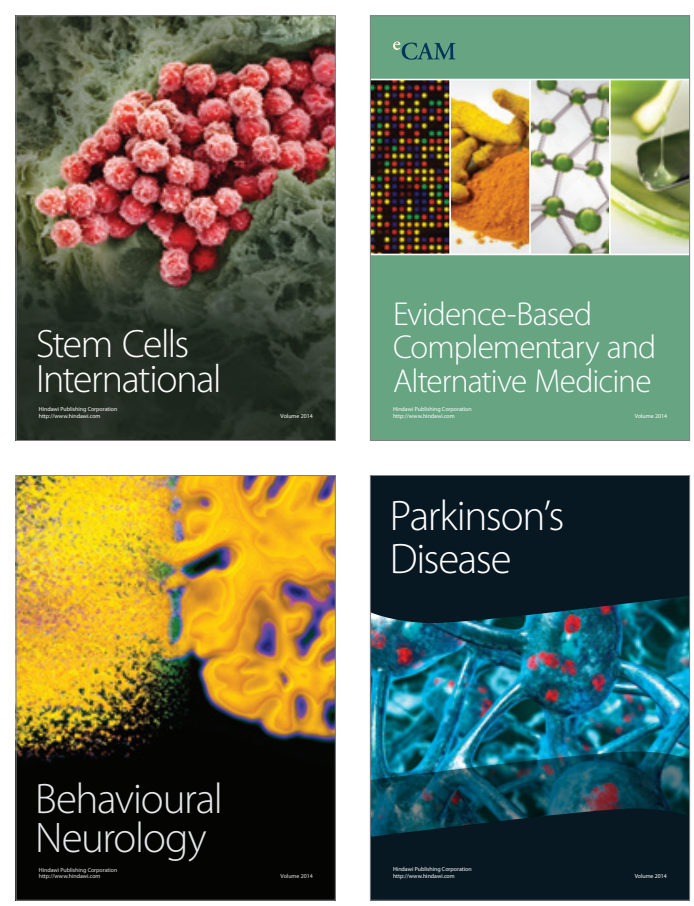

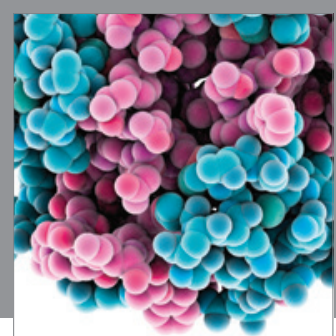

Journal of
Diabetes Research

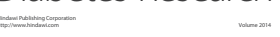

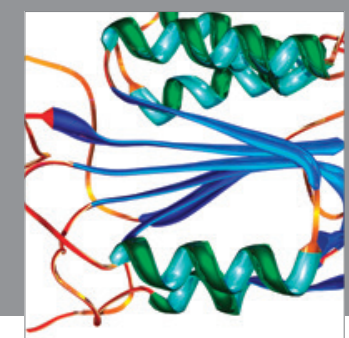

Disease Markers
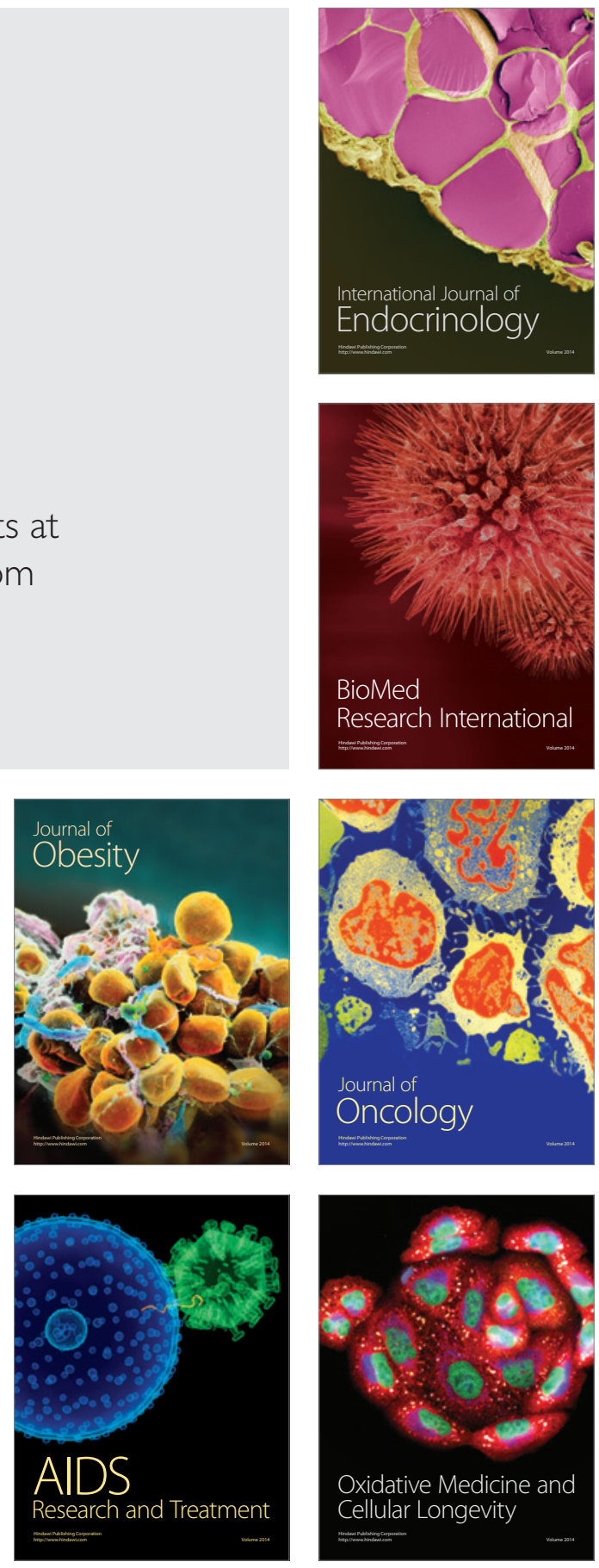